\title{
O mundo musical de Gilberto Gil ${ }^{*}$
}

\author{
ANAÏS FLÉCHET ${ }^{* *}$ \\ Tradução de: \\ SHEYLA CASTRO DINIZ
}

\begin{abstract}
RESUMO: Publicado originalmente em francês como capítulo de livro, o artigo "O mundo musical de Gilberto Gil" recompõe a trajetória de um dos mais célebres músicos brasileiros. $O$ Tropicalismo e a busca do "som universal", o exílio forçado e a tomada de consciência em relação à questão racial, a "descoberta" da África no pós-exílio e os primeiros sucessos além-Brasil, bem como a consagração no cenário internacional e o posterior mandato como ministro da cultura do governo Lula, ganham destaque na análise por constituírem partes fundamentais de um processo que fez de Gilberto Gil uma persona politica e importante mediador cultural no contexto da mundialização.
\end{abstract}

PALAVRAS-CHAVE: Gilberto Gil; Música e política; Relações culturais; Mundialização.

\section{The musical world of Gilberto Gil}

\begin{abstract}
Originally published in French as a chapter of a book, this article "The musical world of Gilberto Gil" reconstructs the trajectory of one of the most celebrate Brazilian musicians. Tropicalism and the search for the "universal sound"; the forced exile and the making of conscience towards racial issue; the "discovery" of Africa in the after-exile and the first hits beyond Brazil, as well as the acclaim in the international scenario and the aftermost mandate as Ministry of Culture in Lula's administration, these elements will be featured in the analysis by constituting fundamental parts of a process that makes Gilberto Gil a political persona and a important cultural mediator in the context of mundialization.
\end{abstract}

KEYWORDS: Gilberto Gil; Music and politic; Cultural relations; Mundialization.

\footnotetext{
* Este artigo foi originalmente publicado como capítulo de livro editado pela Sorbonne. Cf. FLÉCHET, Anaïs. Le monde musical de Gilberto Gil. In: FLÉCHET, Anaïs; LÉVY, Marie-Françoise (orgs.). Littératures et musiques dans la mondialisation, $X^{e}-X X{ }^{e}$ siècles. Paris: Publications de la Sorbonne, p. 231243 , 2015. Nesta tradução, realizada a partir do original, foram incorporadas algumas notas de rodapé sob a indicação Nota da Tradutora [NT].

** Anaïs Fléchet é professora de História na Universidade de Versailles Saint-Quentin-en-Yvelines e pesquisadora, na mesma instituição, do Centro de História Cultural das Sociedades Contemporâneas. Mestre e doutora em História das Relações Internacionais pela Universidade Paris 1 Panthéon-Sorbonne, é autora, dentre outros trabalhos, de Villa-Lobos à Paris: un écho musical du Brésil. Paris: L'Harmattan, 2004; e Si tu vas à Rio: la musique populaire brésilienne en France au XXe siècle. Paris: Armand Colin, 2013, livro reeditado em português sob o título Madureira chorou... em Paris: a música popular brasileira na França do século XX. São Paulo: Edusp, 2018. E-mail: anais.flechet@uvsq.fr ${ }^{* * *}$ Sheyla Castro Diniz é graduada em Música e em Ciências Sociais pela Universidade Federal de Uberlândia, mestre e doutora em Sociologia da Cultura pela Universidade Estadual de Campinas. É autora do livro "... De tudo que a gente sonhou": amigos e canções do Clube da Esquina. São Paulo: Intermeios/FAPESP, 2017; e da tese de doutorado Desbundados \& Marginais: MPB e contracultura nos "anos de chumbo" (1969-1974). Campinas: Unicamp, 2017. E-mail: sheyladiniz@yahoo.com.br
} 
Ásia, África, Bahia, Estados Unidos, Zen-budismo, candomblé, samba e rock'n'roll. Que mais? O som aquariano da new-age misturado ao batuque dos atabaques, os pés descalços fincados na terra e a mente escancarada para o som de outras galáxias nesse limite ilimitado onde a antropologia e o atavismo encontram a metafísica e a informática, cria-se a música de Gilberto Gill1.

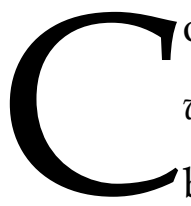

om 27 álbuns gravados e oito Grammy Awards, obtidos nas categorias latin e world music, Gilberto Gil é hoje uma das figuras mais prestigiadas da cultura brasileira no mundo, não só por suas canções e performances artísticas ao longo de mais de cinco décadas como também por sua atuação política, entre 2003 e 2008, como ministro da cultura do presidente Lula. Um mundo que não se restringe às cenas ocidentais, mas abrange todo o hemisfério sul, tal como nos mostra o documentário, lançado em 2013 sob a direção do suíço Pierre-Yves Bourgeaud, Viramundo: uma viagem musical com Gilberto Gil². A câmera segue a jornada do músico baiano de Salvador, sua cidade natal, até às terras áridas do norte da Austrália, onde ele improvisa com um grupo de Aborígenes antes de se juntar, em Johanesburgo, à grande voz da canção engajada sul-africana, Vusi Mahlaseda ${ }^{3}$. Por meio desses e outros encontros, como, por exemplo, com o jamaicano Jimmy Cliff e, mais recentemente, com a beninense Angélique Kidjo4, Gilberto Gil lança uma visão particular sobre o processo de mundialização musical.

A world music tem hoje uma vasta história (cf. FELD, 2004). Nascido em universidades estadunidenses nos anos 1960 para promover o estudo da diversidade musical contra o predomínio da música dita "clássica" - leia-se erudita ou ocidental -, o termo se impôs comercialmente nos anos 1980 e, deste então, constitui parte importante do mercado musical de discos em escala mundial ${ }^{5}$. As etapas desse processo são bastaste conhecidas: a organização do festival Womad - World of Music Art and Dance - na Inglaterra, em 1982; o surgimento de gravadoras especializadas na Europa e nos

\footnotetext{
1 Texto de Caio Fernando Abreu para o encarte do LP Personalidade Gilberto Gil. Philips, 1987.

2 [NT]: O título do documentário, Viramundo, é homônimo ao da canção de Gil em parceria com o letrista José Carlos Capinan, gravada pela primeira vez no LP Louvação (Phonogram, 1967).

${ }^{3} \mathrm{Na}$ metrópole sul-africana, Gil e Vusi Mahlaseda gravaram juntos o CD The South African meeting of Viramundo. Dreampixies, 2013.

${ }^{4}$ Ver: Angélique Kidjo. CD Black Ivory Soul. Sony, 2012. No álbum, gravado no Brasil, Gil interpreta a sua canção "Refavela" em duo com a cantora beninense.

${ }^{5}$ Ver, dentre outros, Taylor (1997).
} 
Estados Unidos na segunda metade daquela década; a introdução da categoria world music nas paradas de sucesso da Billboard Magazine, em 1990; a criação do Grammy Award em 1992; e a primeira Womex - World Music Expo - em Berlin, em 1994. Em termos formais seria difícil definir a world music, já que nesse ramo o que prevalece é a diversidade. Sob tal denominação, encontramos tanto músicas tradicionais de origem relativamente antiga, europeias ou extra-europeias, quanto músicas comerciais produzidas em países do Sul e experiências de fusão levadas a cabo por estrelas do pop internacional, como Peter Gabriel ${ }^{6}$. No seio desse conjunto eclético, dois traços, contudo, são marcantes. A world music é antes de tudo um rótulo que corresponde a um setor preciso do mercado musical, geralmente qualificado de modo negativo em relação ao jazz, à música clássica, às variedades ocidentais, etc. Em contrapartida, há implícito nesse rótulo um imaginário idealizado de encontro, um "mundo de harmonia", de reconciliação humana e miscigenação reivindicada onde a "sinergia entre tradição e modernidade se travestem em música" (MARTIN, 1996; BACHIR-LOOPUYT, 2013). Nessa direção, a world music pode ser considerada um "produto utópico da mundialização" (MALLET, 2004), oriundo, sobretudo, de artistas do Sul e cujo destino comercial é majoritariamente os públicos europeus e norte-americanos (WHITE, 2011).

Estética da diversidade, imaginário dos encontros, imersão nos circuitos de produção internacional: Gilberto Gil parece ilustrar perfeitamente a world music sob esse ângulo. O músico, todavia, não poderia ser reduzido à classificação. Desde o início de sua carreira, Gil defendeu uma concepção moderna da música brasileira, aberta para o mundo, inserida no mercado internacional e na contramão de atribuições exóticas. Destacado mediador cultural, ele contribuiu fundamentalmente para que estilos musicais estadunidenses e africanos fossem assimilados no Brasil e para que a música brasileira fosse projetada no exterior, desenvolvendo ainda reflexões críticas sobre as relações culturais internacionais. Mas qual sentido dar a essa mundialização vista sob a ótica dos trópicos? Como o músico afro-brasileiro estabeleceu vínculos com o mundo no decorrer dos diferentes momentos de sua carreira? E como isso se traduz no plano artístico e no político? A trajetória singular de Gilberto Gil nos instiga a ampliar o nosso

\footnotetext{
${ }^{6}$ [NT]: Famoso músico britânico, ex-vocalista, flautista e líder, entre o final dos anos 1960 e início dos 1970, da banda de rock progressivo Genesis.
} 
olhar para melhor compreender a complexidade das circulações musicais contemporâneas e as diversificadas significações conferidas à world music no espaço atlântico.

\section{O Tropicalismo e a busca de um "som universal"}

Gilberto Passos Gil Moreira nasceu em Salvador em 1942, em uma família de classe média - seu pai era médico e sua mãe professora primária. Ele passa a infância em Ituaçu, pequena cidade do interior baiano, seguindo, ainda criança, para a capital, onde cursa os estudos secundários e universitários ${ }^{7}$. É nessa época que descobre a música: "Esse três - Luiz Gonzaga, João Gilberto e os Beatles foram os marcos de minha formação musical, num sentido profundo" (CONVERSA, 2008, P. 193). Ícone da música nordestina e considerado "rei do baião", Luiz Gonzaga está na origem de suas referências musicais. Espelhando em seu exemplo, Gil aprende a tocar acordeom e forma, com amigos, o grupo Os Desafinados, garantindo a animação de festas de aniversário, escolas e clubes de Salvador. Assim como muitos outros, Gil não passa incólume pelo impacto causado pela bossa nova no final dos anos 1950. Impressionado pela técnica e sensibilidade musical de João Gilberto, ele troca o acordeom pelo violão: “Agora não tem jeito, eu tenho que aprender a tocar violão, eu tenho que fazer isso que esse homem tá fazendo [...]"8. Em 1963, grava seu primeiro disco a convite do produtor Roberto Santana, que o apresenta à nova geração musical da Bahia: Caetano Veloso, Maria Bethânia, Gal Costa e Tom Zé. No ano seguinte, estreia com o espetáculo coletivo "Nós, por exemplo" no Teatro Vila Velha de Salvador. Gil parte logo depois para São Paulo. Lá trabalha por um ano na empresa Gessy Lever antes de se dedicar exclusivamente à carreira musical.

Em 1967, despontam seus primeiros sucessos. Gil grava o LP Louvação pela Phonogram e obtém, com a canção "Domingo no parque", o segundo lugar no III Festival da Música Popular Brasileira9 . A essa altura, sua estética é fortemente influenci-

\footnotetext{
7 [NT]: Em 1964, Gilberto Gil se forma em Administração pela Universidade Federal da Bahia.

${ }^{8}$ Cf. entrevista de Gilberto Gil a Hamilton Almeida (O SONHO, 1972) reproduzida em Cohn (2008, p. 66-67)

${ }^{9}$ As imagens do III Festival da MPB, organizado pela TV Record, estão disponíveis no documentário de Terra e Calil (2010). Para uma análise do festival, conferir Napolitano (2013).
} 
ada pelos Beatles e pela música anglo-saxônica. Ele vislumbra no quarteto de Liverpool, que então incorporava, a um só tempo, o erudito e o popular, a música barroca e o folclore escocês, a vanguarda experimental e o consumo de massa, uma verdadeira "revolução musical"; um formidável "exercício de liberdade" que deveria ser fonte de inspiração para a música popular brasileira (CONVERSA, 2008, p. 81-82). "Manifesto pop" (O SONHO, 1972) sob um arranjo de Rogério Duprat, "Domingo no parque" mesclava o berimbau e as guitarras elétricas dos Mutantes. O efeito no palco - explica Gil - era tanto sonoro quanto visual: "De um lado, os três Mutantes, com os instrumentos elétricos; ao meio, eu, com um violão simples, e do outro lado, o Dirceu, com o berimbau. A usina de um lado. O artesanato no meio. E o primitivismo do outro" (CONVERSA, 2008, p. 198).

O músico pretendia, desse modo, representar a "linha evolutiva da música popular brasileira"10, ideia que, defendida por seu amigo e parceiro Caetano Veloso, colocava-se na contracorrente dos cantores da tradição. Ato político, a utilização da guitarra elétrica estava para além de implicações puramente formais:

Não faço isso em termos de desafio, acho apenas que todas as experiências são válidas na música, vista de maneira universal. [...] Sinto-me hoje como num tribunal, onde sou acusado de trair a verdadeira música popular brasileira. [...] Se pensássemos sempre assim, estaríamos tocando nossas músicas com instrumentos indígenas. É preciso pensar em termos universais. O mundo hoje é muito pequeno, não há razões para regionalismos (GILBERTO, $1967)^{11}$.

Caetano e Gil rompiam com a "linha oficial” da música popular, defendida por críticos tradicionalistas e nacionalistas e por artistas próximos do Partido Comunista Brasileiro (RIDENTI, 2000; NAPOLITANO, 2001 e 2007). Pelo menos desde os anos 1950, críticos conservadores - tenazes partidários da "música de raiz" - se voltavam contra a "expropriação da música popular" pela classe média, bem como contra a consequência inevitável que isso, aos seus olhos, acarretaria: a perda de toda a originalidade. Já na década seguinte, os chamados músicos engajados se lançaram numa espécie de "combate cultural" contra a "invasão da música internacional nos países

\footnotetext{
${ }^{10}$ Expressão empregada por Caetano Veloso num debate promovido pela revista Civilização Brasileira (QUE CAMINHO, 1966).

${ }^{11}$ Entrevista reproduzida em Cohn (2008, p. 14-15).
} 
subdesenvolvidos"12, notadamente o rock e sua versão local, o iê-iê-iê. Essas tomadas de posição desembocaram na "marcha contra a guitarra elétrica". Sob uma grande faixa que, em letras garrafais, indicava "Frente única da música popular brasileira", o episódio, em julho de 1967, reuniu nas ruas do centro de São Paulo a fina flor da MPB13. Sinal de instabilidade dos tempos, Gil participa dessa manifestação pouco antes de compor "Domingo no parque". Num depoimento recente, ele justifica o gesto paradoxal pela afeição que nutria por Elis Regina, uma das principais instigadoras da marcha (TERRA; CALIL, 2010). Após o festival, em setembro, as diferenças estariam, todavia, claramente fixadas. Em torno de Caetano e Gil, afirma-se um movimento de modernização da música brasileira, em que a bricolagem de elementos diversificados é assumida em detrimento das barreiras do "bom gosto" e da "mística revolucionária", em que o "som universal" é celebrado contra todas as tentativas de retorno à "pureza original" da música popular (O SOM, 1967).

O conjunto dessas experiências se consolida em 1968, dando origem ao tropicalismo ${ }^{14}$. Liderado pelos dois baianos, o movimento musical reivindica a herança do modernismo brasileiro, sobretudo no que tange ao Manifesto Antropofágico de Oswald de Andrade, texto fundador de 1928 cujas frases iniciais lançavam uma provocação: “Tupi or not tupi? That is the question”. À semelhança dos índios Tupinambás, que devoraram seus inimigos para se impregnar de sua força vital, os artistas brasileiros deveriam "canabalizar" as tradições indígenas, africanas e europeias para assim criar uma cultura original, que não fosse mera cópia de modelos europeus e nem simples reprodução de um folclore obsoleto. No LP coletivo Tropicália ou Panis et circencis, de 1968, o tropicalismo celebra certa "estética da miscigenação". Além de Gil e Caetano, o álbum reúne os baianos Tom Zé e Gal Costa, o músico e arranjador de formação

\footnotetext{
${ }^{12}$ A expressão é de Ferreira Gullar em Que Caminho (1966).

13 [NT]: A sigla MPB (Música Popular Brasileira) surge por volta de 1965, início da "era dos festivais", para designar um conjunto de canções heterogêneas que, de uma maneira ou de outra, partilham do "nacional-popular", ideário cujos aspectos mais prementes, grosso modo, são o engajamento de esquerda, a denúncia das injustiças sociais e a valorização da cultura musical brasileira. Sobre o assunto, ver, dentre outros, Napolitano (2001) e Contier (1998). Antes da investida tropicalista, o "grupo baiano" liderado por Caetano e Gil estava em conformidade com o nacional-popular e com o que se entendia por MPB, como atesta, por exemplo, o espetáculo, do qual participaram, Arena canta Bahia, em cartaz em São Paulo, em 1965, sob a direção de Augusto Boal.

14 Ver especialmente Favaretto (2000), Calado (1997) e Dunn (2001).
} 
erudita Rogério Duprat, a "musa da bossa nova" Nara Leão ${ }^{15}$, os jovens roqueiros Mutantes e os poetas e letristas José Carlos Capinan e Torquato Neto. O experimentalismo dá o tom das canções variadas que integram o disco. As letras, nas quais sobressaem paródias e pastiches, propõem uma releitura compacta da história cultural brasileira, incluindo poetas românticos do século XIX e o kitsch de Carmen Miranda. Os arranjos inusuais, por sua vez, passam ao largo de hinos revolucionários, dialogando concomitantemente com a música clássica e com a estética pop. Expressão de uma liberdade de criação, essa "Geleia geral" - para citar a canção de Gil e Torquato, faixa do disco borra as fronteiras entre erudito e popular, entre influências estrangeiras e música nacional $^{16}$. Movimento híbrido e de absorção, o tropicalismo foi um momento ímpar de aculturação da música anglo-saxônica no Brasil.

A ousadia dos tropicalistas, contudo, durou pouco. O regime militar instaurado em 1964 conhece um duro efeito, sem precedentes, com a edição do Ato Institu-

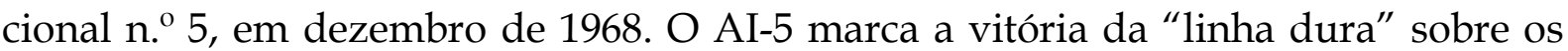
militares moderados, iniciando o período mais intenso da repressão política. Dentre outras medidas arbitrárias, o "golpe dentro do golpe" suspendeu o habeas corpus e impôs a censura prévia aos meios de comunicação ${ }^{17}$. Um tanto quanto poupada no pré68, a produção artística passa a ser igualmente alvo privilegiado dessa nova fase repressiva. Ainda que as canções tropicalistas não fossem explicitamente políticas, Caetano e Gil estavam entre os músicos tachados pelos órgãos de vigilância como "perigosos agentes filo-comunistas", incentivadores de uma "ação nefasta sobre o público brasileiro"18. Naquele mesmo dezembro de 1968, ambos são detidos, em São Paulo, sob a acusação de terem desrespeitado a bandeira brasileira num de seus espetáculos. Após dois meses de prisão no Rio de Janeiro e outros quatro de confinamento em Salvador, eles são "convidados", em junho de 1969, a deixar o país (cf. VELOSO, 1997, p.

\footnotetext{
15 [NT]: Antes de aderir indiretamente ao tropicalismo, Nara Leão, de "musa da Bossa Nova" torna-se símbolo da canção engajada (ou de protesto) ao protagonizar a primeira temporada do Show Opinião, escrito por Vianninha e estreado no Rio de Janeiro em dezembro de 1964.

16 "Geleia geral" designa um fenômeno mais abrangente de hibridismo cultural. [NT]: O termo, que veio a se tornar título da canção de Gil e Torquato, foi cunhado pelo poeta concretista Décio Pignatari na revista Invenção, em 1967: "Alguém tem que ser medula e osso na geleia geral brasileira".

${ }^{17}$ Sobre a política repressiva do regime ditatorial, ver especialmente Fico (2001).

${ }^{18}$ Nota do II Exército de São Paulo, 1967, citada por Marcos Napolitano (2004, p. 110).
} 
347-409; 413) ${ }^{19}$. Começam então os anos de exílio na Europa. Depois do desembarque em Portugal, passam um curto período na França e se instalam em Londres, onde residem até janeiro de 1972.

\section{Exílio: uma escola musical}

Enquanto a maioria dos exilados brasileiros prefere se fixar em Paris, Gil e Caetano optam por Londres, uma escolha relacionada com questões estéticas e políticas: “Em Paris, a situação ainda era tensa devido aos acontecimentos de 1968. Policiais pediam documentos a cada esquina [...]. Já Londres parecia uma cidade tranquila, calma e cuja cena musical era bem mais interessante" 20. Em Londres, Gil mergulhou no universo sonoro que, de longe, no Brasil, admirava. Para ele, o exílio foi um tempo de grande aprendizado, principalmente no que diz respeito ao seu instrumento violão, como ele explicaria em 1972:

Acho que evoluí mesmo. No Brasil, eu era um fazedor de músicas e tocava violão incidentalmente. Não tinha oportunidade de me aprofundar no instrumento. Eu me assustei, ao chegar à Inglaterra, com o nível, a qualidade, o acabamento da música que se fazia aqui. O meu nível não era nada comparado com o da praça. Hoje, eu sou um instrumentista. [...] Tive contato com outros instrumentistas, [eu] ia em tudo quanto era festival, armando minha barraquinha. Passei do palco para a plateia, o que de certa maneira foi fundamental para o meu processo de absorção. (AS EXPERIÊNCIAS, 1972, p. 67) ${ }^{21}$.

Londres torna-se uma "escola musical"; uma cidade que "impregna" Gil com sua atmosfera pop: “Tudo me ensinava [...]. De repente, vinha na minha cabeça assim: os Beatles fizeram isso, Jimi Hendrix também fez isso [...]. ‘Puxa vida, Mick Jagger cantou nesse palco'" (O SONHO, 1972, p. 92). Nem por isso, o exílio deixa de ser um tempo frutífero para a criação. Além de tocar na sala de concerto londrina Royal Festival Hall e no Festival da Ilha de Wight, em 1970, e realizar ainda alguns shows na França, Suíça, Alemanha, Áustria, Dinamarca e Suécia, Gil grava, em 1971, um álbum

\footnotetext{
19 [NT]: Embora Gil e Caetano não tenham sido encarcerados em Salvador, eles estavam expressamente proibidos de sair da cidade, o que impedia o prosseguindo de suas carreiras artísticas.

${ }^{20}$ Cf. Caetano Veloso em entrevista a Anaïs Fléchet, Rio de Janeiro, 23 abr. 2005.

${ }^{21}$ Entrevista de Gil a Bernardo Kucinski, reproduzida em Cohn (2008, p. 45).
} 
todo em inglês nos estúdios londrinos Chappell ${ }^{22}$. Nesse mesmo ano, apresenta-se pela primeira vez em Nova York. Tudo isso lhe proporciona certa projeção internacional, não obstante sua música permanecesse pouco conhecida tanto na Europa quanto nos Estados Unidos. Seu álbum londrino vende pouco e, nos shows, seu público era formado basicamente por brasileiros exilados ou latino-americanos (O SONHO, 1972, p. 91).

No Brasil, a situação é diametralmente oposta. "Aquele abraço", samba de despedida que Gil gravara antes de deixar o país, alcança o topo das vendas, chegando a receber, em 1970, o “Golfinho de ouro", importante prêmio musical concedido pelo Museu da Imagem e do Som do Rio de Janeiro. Gil, contudo, rejeita veementemente a distinção. Numa longa carta publicada no semanário satírico O Pasquim, ele, de Londres, critica a linha tradicionalista do Museu e, de quebra, as instituições brasileiras submissas às autoridades militares:

O Museu realmente pensa que "Aquele abraço" é samba de penitência pelos pecados cometidos contra "a sagrada música brasileira". [...] O museu continua sendo o mesmo [...]: tutor do folclore de verão carioca. Eu não tenho porque não recusar o prêmio dado para um samba que eles supõem ter sido feito zelando pela "pureza" da música popular brasileira. Eu não tenho nada com essa pureza. Tenho três LPs gravados aí no Brasil que demonstram isso. E que fique claro para os que cortaram minha onda e minha barba que "Aquele abraço" não significa que eu tenha me "regenerado", que eu tenha me tornado "bom crioulo puxador de samba", como eles querem que sejam todos os negros que realmente "sabem qual é o seu lugar". Eu não sei qual é o meu e não estou em lugar nenhum; não estou mais servindo a mesa dos senhores brancos [...]. Para mim, o Museu e o nazi-fascismo comem no mesmo prato [...] (GILBERTO GIL, 1970) ${ }^{23}$.

À denúncia da visão nacionalista, da "pureza" da música brasileira, já presente no tropicalismo, Gil adiciona um elemento racial até então ausente em suas declarações. Antes de partir para a Europa, ele se sentia "pouco tocado pela consciência negra", já que - concluía - jamais sofrera racismo no Brasil tendo em vista sua condição

\footnotetext{
${ }^{22}$ Cf. LP Gilberto Gil. Famous Music/Phonogram, 1971. [NT]: Exceto "I can't find my way home", de Steve Windwood, todas as oito canções são autorais, sendo que três têm letras de Jorge Mautner. Na versão em CD do disco, lançada em 1998 pela Mercury (pertencente à Universal Music Group, antiga Phonogram), foram incluídas interpretações de Gil, registradas ao vivo, para "Up from the skies", de Jimi Hendrix, e "Sgt. Pepper's Lonely Hearts Club Band", de John Lennon e Paul McCartney.

${ }^{23}$ Carta reproduzida em Cohn e Coelho (2007, p. 233).
} 
social de classe média (GIL FALA, 1969)24. É em Londres que a questão racial o interpela. Isso graças, sobretudo, aos contatos que mantém com ativistas estadunidenses e às informações pujantes sobre os movimentos de independência africana (TROPICÁLIA $^{25}$. Para Gil, essa tomada de consciência vem acompanhada de uma autocrítica sobre suas origens, bem como de uma interrogação sobre o lugar ocupado pela América Latina no mundo. Dessas reflexões surge um interesse renovado pela cultura afro-brasileira, que o músico se dispõe então a melhor conhecer ao regressar do exílio:

Eu nunca tinha ido ao candomblé. Só fui depois do exílio. Aí é que me aproximei dos blocos, do significado profundo do carnaval da Bahia. [...]. Isso [a consciência negra] culminou em mim quando saí nos Filhos de Gandhi. Depois fui ao Festival de Artes Negras na África. E aí vem Refavela, que é o primeiro manifesto negro, não é? (in COHN, 2008, p. 253-254).

O exílio, portanto, agrega múltiplos significados à trajetória de Gil. “Escola de música pop", Londres é também o lugar do descobrimento do reggae e da retomada, sob outra perspectiva, da cultura musical afro-brasileira. A Europa conduz o músico para a África: primeiro no Brasil, ao engajar-se no "movimento de africanização do carnaval da Bahia"26, e depois em Lagos, na Nigéria, ao participar da segunda edição do Festival Mundial de Artes Negras, em fevereiro de 1977.

\section{A descoberta da África e a projeção nas cenas internacionais}

Na esteira das independências africanas, o I Festival Mundial de Artes Negras reuniu em 1966, em Dakar, Senegal, artistas e intelectuais negros dos cinco continentes (FIQUET, Eloi; GALLIMARDET, 2010 e COQUERY-VIDROVITCH, 2013). O evento, concebido por Alioune Diop e Léopold Sédar Senghor como uma manifestação de "defesa da importância da negritude", teve por objetivo afirmar a independência cultural da África. Convidada de honra do festival, a Nigéria é escolhida para sediar

\footnotetext{
${ }^{24}$ Entrevista de Gil a Odete Lara reproduzida em Cohn (2008, p. 38).

${ }^{25}$ Cf. "Tropicália revisitada". Entrevista concedida a Ana de Oliveira para o site Tropicália. Disponível em: <http://tropicalia.com.br/ilumencarnados-seres/entrevistas/gilberto-gil-2>; e reproduzida em Cohn (2008, p. 254).

${ }^{26}$ Conferir Agier (2000). Esse aspecto é particularmente sensível a Gilberto Gil após seu retorno ao Brasil, como nos mostram os LPs Cidade do Salvador (Phonogram, 1973) e Gil \& Jorge (Phonogram, 1975). Refazenda (Phonogram, 1975), por sua vez, destaca-se pela intensa exploração de ritmos nordestinos, algo já anunciado em Expresso 2222 (Phonogram, 1972), seu primeiro disco pós-exílio.
} 
sua segunda edição, adiada, no entanto, pelo golpe militar de janeiro de 1966 e pela deflagração, no ano seguinte, da guerra civil Nigéria-Biafra. O II Festival Mundial de Artes Negras só ocorre, finalmente, em 1977, já sob a égide do novo presidente do país, o general Olusegun Obasanjo. Nessa segunda edição, a noção de negritude é abandonada para dar lugar ao pan-africanismo e à celebração dos elos orgânicos entre o continente e a diáspora negra, orientação conhecida como Black Unity.

O caráter político do evento não é, de modo algum, ignorado pela Nigéria, que dele pretendia se servir para marcar sua liderança - e a de outros países envolvidos nessa que foi chamada de "exposição universal negra"27 - no âmbito da Organização da Unidade Africana. Como fizera na primeira edição, de 1966, o Brasil envia delegações ao festival. O intuito não era outro senão promover uma boa política internacional e sustentar sua posição estratégica no Atlântico Sul (SARAIVA, 1996). Indicados a dedo pelo Ministério das Relações Exteriores, artistas e intelectuais deveriam expressar "as relações históricas e humanas entre África e Brasil”. Capoeira, escolas de samba cariocas e o candomblé da Bahia são representados, e, também, a bossa nova, na voz da cantora Elizeth Cardoso, e a canção pós-tropicalista, com Gilberto Gil. Crítico da ditadura, preso, exilado e não imune da censura no pós-exílio ${ }^{28}$, Gil é oficialmente convidado pelo ministério do governo Geise ${ }^{29}$ para participar do evento - convite do qual se pode apreender o contraste marcante entre a política interna do regime militar e as ações da diplomacia cultural brasileira ${ }^{30}$. Mas nem todos os brasileiros negros presentes em Lagos eram benquistos pelo ministério. Ativista exilado nos Estados Unidos e, em 1977, pesquisador convidado na Universidade Nigeriana de Ife, Abdias do Nascimento foi declarado persona non grata no festival. Sua denúncia do racismo no Brasil

\footnotetext{
27 Expressão empregada por Apter (2005).

28 [NT]: Para dar dois exemplos, Gilberto Gil e Chico Buarque são censurados em pleno palco, em maio de 1973, ao tentarem entoar a canção "Cálice" (parceria dos dois músicos) no Phono 73, evento promovido pela Phonogram com os artistas de seu elenco. Ver: Phono 73: o canto de um povo; DVD, 35 min., Universal, 2005. Já em 1976, época em que, com Caetano, Gal Costa e Maria Bethânia, excursiona com o show Doces Bárbaros, Gil é detido em Florianópolis, constrangido à internação, por alguns dias, num sanatório, e por pouco não escapa da condenação a um ano de prisão por porte de maconha. Conferir: O Fumo (1976), entrevista de Gil a João Santana Filho, reproduzida em Cohn (2008, p. 104-139).

${ }^{29}$ [NT]: À frente do Ministério das Relações Exteriores do governo Geisel estava o diplomata Azeredo da Silveira.

30 Para mais informações, consultar Fléchet (2012).
} 
feria a imagem de país mestiço que o ministério desejava transmitir aos seus interlocutores africanos ${ }^{31}$.

Em que pese a relevância dessas questões políticas, o II Festival Mundial de Artes Negras foi uma experiência singular para Gilberto Gil. Ao retornar de Lagos, ele grava Refavela (Phonogram, 1977), que, em suas palavras, é um LP conceitual:

[...] Essa coisa de arte dos trópicos, comunidades negras contribuintes para a formação de novas etnias e novas culturas no Novo Mundo: Brasil, Caribe, Nigéria, Estados Unidos..., todas essas coisas, essas culturas emergentes como presença forte do dado negro. [...] O disco teria uma ideologia explícita, básica, que é essa minha, esse aspecto confessional do meu estado existencial [...]. Mas [ao contrário das pessoas da imprensa], eu não colocaria tanto como ideológico, mas como temático, que é essa coisa black, black jovem, Black Rio... $(\mathrm{A} \text { PAZ, 1977) })^{32}$.

Fruto do "constante feedback das culturas do mundo moderno globalizado", Refavela mescla sonoridades do Atlântico negro33: "Ilê Ayê", canto afro do carnaval de Salvador; o reggae "No norte da saudade", "Balafon”, uma homenagem à juju music nigeriana, e "Samba do avião", bossa nova de Tom Jobim revisitada sob um ritmo funk. Por meio dessas diferentes canções, Gil aventa um "cosmopolitismo moderno" fundado sobre a miscigenação, em oposição a todo tipo de "nacionalismo negro". Como no tropicalismo, sua perspectiva continua universal: “É aquilo que eu digo, 'brasileirinho pelo sotaque, mas de língua internacional'” (A PAZ, 1977, p. 148).

É justamente após o lançamento de Refavela que Gil desponta, de fato, no cenário internacional. Em 1978, sua apresentação no festival de Montreux dá origem a um LP duplo, gravado ao vivo ${ }^{34}$, cuja repercussão é interessante na Europa. Tão logo volta da Suíça, parte para a Califórnia onde grava Nightingale, seu primeiro disco norte-americano lançado um ano depois pela WEA (EU QUERO, 1979) ${ }^{35}$. Ademais de faixas originais em inglês, Nightingale traz canções já registradas em trabalhos anteriores, sendo que duas são de Refavela ("Alapalá" e “Balafon”). Com a recepção crítica

\footnotetext{
31 Abdias do Nascimento detalha esse episódio em "Prólogo: a história de uma rejeição" (NASCIMENTO, 1978, p. 25-40).

32 Entrevista reproduzida em Cohn (2008, p. 143; 146). [NT]: Surgida no Rio de Janeiro em 1976, com o apoio da gravadora WEA, a banda Black Rio realiza uma fusão original de samba, sonoridade das orquestras de gafieira, jazz, grooves de funk estadunidense e soul music. Sobre a banda, ver, por exemplo, Zan (2005).

33 Para uma abordagem dessa noção, conferir Gilroy (2003, p. 10; 33; 105-153).

${ }^{34}$ Cf. LP Gilberto Gil ao vivo em Montreux. Warner/Elektra, 1978 [NT].

35 Entrevista de Gil a Décio Bar e Regina Echeverria reproduzida em Cohn (2008, p. 156 e ss).
} 
favorável, Gil realiza, em 1979, uma turnê de dois meses pelos Estados Unidos. Na Califórnia, grava ainda Realce (WEA, 1979), este caracterizado pela influência de nomes do pop-rock como Stevie Wonder, Nathan East e Abe Laboriel, artistas que encontra ao longo da divulgação de Nightingale.

Gilberto Gil se consagra, desde então, como um importante mediador cultural, estabelecendo pontes entre Brasil, Europa, África e entre países do continente americano como um todo. Sobre essas pontes é que desenvolve sua carreira internacional a partir dos anos 1980, multiplicando os shows na Europa e na América do Norte e alcançando, em grande escala, o mercado internacional com trabalhos como Gilberto Gil Unplugged (1994), um CD que, lançado pela WEA, vem acompanhado de um DVD musical produzido pela MTV. Em 1998, recebe o seu primeiro Grammy Award por Quanta (WEA, 1997), considerado o melhor disco de world music daquele ano. Respectivamente em 2001 e 2005, ganha novamente o Grammy pelos discos Gil e Milton ${ }^{36}$ e Eletroacústico. Não bastasse isso, Gil foi um dos músicos mais premiados na categoria “Música Brasileira” desde a criação, em 2000, do Latin Grammy Award37.

\section{Um músico diplomata?}

Paralelamente à sua atividade musical, Gilberto Gil se compromete com a vida política desde a transição democrática nos anos 1980. Em 1979, quando a ditadura dá os primeiros sinais de arrefecimento com a Lei da Anistia aos presos e exiliados políticos, Gil integra o Conselho Estadual de Cultura da Bahia. É preciso, todavia, esperar a saída dos militares para que a sua atuação política se intensifique. Em 1987, assume a direção da Fundação Gregório de Matos, órgão ligado à Secretaria Municipal de Cultura e Turismo de Salvador, e, no ano seguinte, lança-se como pré-candidato a prefeito da cidade. Embora sua candidatura tenha sido descartada, em 1989 é eleito vereador do município pelo Partido do Movimento Democrático Brasileiro (PMDB). Como vereador, propõe diversos projetos voltados para o meio ambiente, o que vai

\footnotetext{
36 [NT]: Reconhecido internacionalmente, Milton Nascimento é outro músico negro brasileiro que, pelo menos desde os anos 2000, vem sendo associado à world music no mercado discográfico europeu e estadunidense.

${ }^{37}$ Conferir site: https://www.latingrammy.com/en.
} 
culminar, em 1990, em sua filiação ao Partido Verde (PV). Findado o mandato em 1992, Gil torna a se dedicar inteiramente à carreira musical. Exceto por um breve período como Ministro da Ecologia do governo Fernando Henrique Cardoso, ele não se incumbe de nenhum cargo político de destaque até 2003.

A eleição de Lula e, consequentemente, a chegada do Partido dos Trabalhadores (PT) ao poder suscitam novas esperanças na população brasileira, incluindo os artistas que, numerosos, apoiaram a campanha do novo presidente. Gil diz ter ficado surpreso quando Lula lhe sugeriu a pasta de ministro da cultura, não hesitando por muito tempo, porém, a aceitar a empreitada ${ }^{38}$. Seu ministério é marcado por vários projetos inovadores, como a criação dos Pontos de Cultura - pequenos centros culturais, espalhados pelo Brasil, destinados a democratizar o acesso às culturais digitais ${ }^{39}$ - e o revival do debate sobre a propriedade intelectual gerado pela sua defesa das licenças Creative Commons ${ }^{40}$. A persona de Gil como ministro, como ele mesmo reconhece, é igualmente significativa para a afirmação da presença da cultura brasileira nas cenas internacionais. Sob sua gestão, estruturas específicas são canalizadas para o ministério. Em 2006, por exemplo, é fundado o Comissariado da Cultura Brasileira no Mundo, que visa a "coordenar a participação brasileira nas manifestações internacionais, divulgar a imagem do Brasil no mundo e promover a exportação de bens culturais" 41 , funções que, anteriormente, eram apenas da responsabilidade do Ministério das Relações Exteriores. Em 2008, o Comissariado toma parte de uma ambiciosa Direção das relações internacionais, encarregada de definir as diretrizes da política brasileira no exterior e de assegurar a mediação com o Ministério das Relações Exteriores ${ }^{42}$.

Gil não se furta de sua notoriedade artística quando se trata de colocá-la a serviço da ação política internacional. Durante seu mandato, realiza vários concertos, fazendo questão de distinguir, entretanto, os que são estritamente profissionais dos

\footnotetext{
${ }^{38}$ Cf. Gilberto Gil, na ocasião de uma mesa-redonda sobre Sartre, na qual o músico era convidado especial, na Escola Normal Superior de Paris, 23 abr. 2013.

39 [NT]: Os Pontos de Cultura foram desenvolvidos, a pedido do ministro Gil, pelo historiador e escritor Célio Turino. Para informações, ver Turino (2010).

${ }^{40}$ Sobre o assunto, ver Costa (2011).

${ }^{41}$ Cf. Decreto presidencial, 27 de setembro de 2006. Disponível em: https://www.planalto.gov.br/ccivil_03/_Ato2004-2006/2006/Dnn/Dnn10988.htm.

${ }^{42}$ Cf. Decreto n. ${ }^{\circ}$ 6.368, de 30 de janeiro de 2008, artigo sexto. Disponível em: https://www.planalto.gov.br/ccivil_03/_Ato2007-2010/2008/Decreto/D6368impressao.htm.
} 
que são oficiais (GILBERTO GIL, 2007) ${ }^{43}$. Os primeiros, conforme declarou à imprensa, provocando polêmicas, têm por objetivo complementar o salário que recebe do ministério. Já nos outros, ele não é remunerado, pois age na condição de membro do governo, associando a música às suas funções políticas. Em setembro de 2003, o ministromúsico canta na Organização das Nações Unidas, em Nova York, em tributo ao diplomata brasileiro Sérgio Vieira de Mello e às outras 21 vítimas do atentado, no mês anterior, à sede da ONU em Bagdá. Português, espanhol, francês e inglês alternam-se nas 16 canções de seu repertório, dentre elas "Imagine", de John Lennon, e "No woman, no cry", de Bob Marley. Em sua voz, destaca-se ainda a leitura de uma mensagem de paz em que critica duramente a guerra iniciada pelos Estados Unidos, seis meses antes, contra o Iraque: “Não faz sentido pensar em segurança sem pensar em justiça; não faz sentido pensar em segurança sem pensar em respeito ao outro" (apud COSTA, 2011, p. 41). Gil surpreende a assembleia ao final do concerto ao chamar o diplomata ganense Kofi Annan, então secretário geral da ONU e Nobel da Paz em 2001, para acompanhálo na percussão ${ }^{44}$. A imagem emblemática dos dois homens dividindo o palco exprime a convicção, por ambos partilhada, de que a música é fator de aproximação e reconciliação.

A música, entretanto, é também peça-chave para garantir uma melhor visibilidade do Brasil no exterior. Sob esse ponto de vista, o Ano do Brasil na França é exemplar. Promovida pelos ministérios das Relações Exteriores e da Cultura, a manifestação atinge o ápice na noite do dia 13 de julho de 2005, quando é realizado um grande show gratuito na Praça da Bastilha (LESPRIT, 2005). Na presença dos presidentes Lula e Jacques Chirac, e diante de uma multidão entusiasta, Gil entoa o hino francês, La Marseillaise, na companhia de artistas como Jorge Mautner, Gal Costa, Jorge Ben, Lenine e Daniela Mercury ${ }^{45}$. Divulgador da música brasileira na França desde os anos 1940, Henri Salvador também adere à celebração, autenticando a longa história

\footnotetext{
${ }^{43}$ Reproduzida em Cohn (2008, p. 266).

${ }^{44}$ Para ver o final do concerto, conferir: https://www.youtube.com/watch?v=zwFQkohi3Wk.

${ }^{45}$ Para ver as imagens, conferir: https://www.youtube.com/watch?v=aRkKxHDkwUM.
} 
de relações culturais entre os dois países ${ }^{46}$. No coração da festa nacional francesa, a música funciona aqui como um potente soft power 47 brasileiro.

A diplomacia cultural brasileira não se limita, todavia, às cenas ocidentais. Em 2007, o Comissariado de Cultura Brasileira no Mundo estabelece suas prioridades: promover o Mercosul cultural ${ }^{48}$, afirmar o lugar do Brasil como líder da lusofonia no seio da Comunidade dos Países de Língua Portuguesa ${ }^{49}$, defender suas posições frente à Unesco e fortalecer as cooperações culturais com a África ${ }^{50}$. É sob a perspectiva dessa diplomacia Sul-Sul que o Brasil participa, em 2010, da terceira edição do Festival Mundial de Artes Negras, em Dakar. Inicialmente prevista para 2006, essa terceira edição só acontece quatro anos depois, o que certamente explica a ausência de Gilberto Gil na capital senegalense. De todo modo, é durante seu ministério que o projeto do presidente Abdoulaye Wade ganha forma. Através do Comissariado e da Fundação Cultural Palmares - criada em 1988 para promover e preservar a cultura afro-brasileira -, o Brasil, convidado de honra do festival, integra-se à sua organização desde 2007. Em maio de 2009, Gil não apenas marca presença no lançamento brasileiro da manifestação em Salvador, tendo ao lado Lula e Wade, como compõe, em francês, o hino do evento "La renaissance africaine" ("O renascimento africano"). A ocasião é propícia para que Lula reforce sua vontade de cooperação econômica com países africanos. Não só o faz como convoca seu congênere senegalês a apoiar a candidatura do Brasil para os Jogos Olímpicos de 2016.

O hino do III Festival Mundial de Artes Negras está para além, no entanto, das relações bilaterais entre Brasil e Senegal, assim como está para além dos interesses políticos estratégicos envolvendo o evento. Desde 2008, Gil retomou a canção três vezes em seus discos solos, valendo-se de arranjos distintos ${ }^{51}$. No já citado documentário

\footnotetext{
46 Para mais informações, consultar Fléchet (2013).

${ }^{47}$ [NT]: Em termos sucintos, soft power, expressão hoje corriqueira entre estudiosos das Relações Internacionais, diz respeito às habilidades de persuasão e influência que um país - no caso, o Estado brasileiro em relação à França - dispõe sobre outro. Ao contrário do que seria o hard power - imposição pela força -, aqui o poder ou os interesses políticos são mediados pela cultura, língua e/ou ideologias. O conceito foi desenvolvido por Nye (2004).

${ }^{48}$ Sobre o assunto, consultar Soares (2008, p. 53-69).

${ }^{49}$ Para saber mais, consultar Marques (2012).

50 Cf. Coutinho (2008). Sobre a política brasileira voltada para a África, ver Lafargue (2008) e Saraiva (2012).

${ }^{51}$ Cf. Gilberto Gil. CD Banda larga cordel. Geleia Geral/Warner, 2008; CD Banda dois. Geleia Geral/ Warner, 2009; CD Concerto de cordas e máquinas de ritmo. Geleia Geral/Biscoito Fino, 2012.
} 
Viramundo, ele a interpreta junto à Miagi Youth Orchestra, formada por jovens músicos sul-africanos negros, brancos e mestiços, símbolo da reconciliação nacional da África do Sul. "La renaissance africaine" figura ainda no disco registrado Gil e Vusi Mahlaseda em Johanesburgo.

Esse elogio da África no despertar do século XXI, de "seu povo e território que se estendem na diáspora até o fim da terra" - como diz a letra de Gil ${ }^{52}$-, ocupa um lugar significativo no trabalho de nosso artista: músico e ativista político que se torna testemunha privilegiada e ator maiúsculo do processo de mundialização cultural contemporâneo. O tropicalismo, o exílio e o renascimento africano são, portanto, aspectos cruciais para se compreender o papel do músico no mundo e a variedade de reapropriações culturais de que se nutre em suas obras. Fundada sobre a mistura de timbres e ritmos, a arte de Gilberto Gil atesta a relevância do aspecto político no processo de mundialização musical, bem como a vitalidade das trocas culturais no espaço atlântico, trocas não circunscritas ao circuito comercial Norte-Sul da world music.

\section{Referências}

A PAZ doméstica de Gilberto Gil. O Globo, 10 ago. 1977.

AGIER, Michel. Anthropologie du carnaval: la ville, la fête et l'Afrique à Bahia. Paris: Parenthèses, 2000.

\footnotetext{
52 [NT]: Eis a letra completa, no original em francês e, na sequência, a tradução para o português: "L'homme plein de dignité/ Sa nature, ses dieux/ Son histoire et l'au delà/ L'homme et son paysage aimé/ Tout est là devant ses yeux/ Tout dedans le baouba/ La renaissance africaine/ La renaissance africaine/Et sa puissance/La renaissance africaine/La renaissance africaine/Avec sa dance/ C'est l'Afrique libertée/ C'est l'Afrique et ses idées/ De sagesse et de vigueur/ C'est l'Afrique et sa mission/ Clé pour la vrai construction/ Du monde civilizé/ Son peuple, son territoire/ Qui s'étendent en diaspora/ Jusqu'à la fin de la terre/ En Europe, en Amerique/ C'est toujour l'esprit d'Afrique/ La nouveauté qui prospère/ Ses enfants, ses gens musclés/ Ses femmes d'outre beauté/ Une beauté noir-nuit/ Continent le plus agé/ Les vieux temps nous ont laissé/ Sa mythologie, sa vie". Tradução: "O homem pleno de dignidade/ Sua natureza, seus deuses/ Sua história e tudo o mais/ O homem e sua paisagem amada/ Tudo diante de seus olhos/ Tudo dentro do baobá/ O renascimento africano/ $O$ renascimento africano/ $E$ sua potência/O renascimento africano/O renascimento africano/Com sua dança/É a África liberta/É a África e suas ideias/ De sabedoria e de vigor/É a África e sua missão/ Chave para a verdadeira construção/ Do mundo civilizado/ Seu povo, seu território/ Que se estendem na diáspora/ Até o fim da terra/ Na Europa, na América/ Há sempre o espírito da África/ A novidade que prospera/ Suas crianças, sua gente forte/ Suas mulheres de uma outra beleza/ Uma beleza negra-noite/ O continente mais antigo/ Os velhos tempos nos legaram/ Sua mitologia, sua vida".
} 
APTER, Andrew. The Pan-African Nation: oil and the spectacle of culture in Nigeria. Chicago: The University of Chicago Press, 2005.

AS EXPERIÊNCIAS e a volta de Gilberto Gil. Veja, 19 jan. 1972. Entrevista de Gil a Bernardo Kucinski.

BACHIR-LOOPUYT, Talia. Une musique du monde faite en Allemagne?: les compétitions créoles et l'idéal d'une société plurielle dans l'Allemagne d'aujourd'hui. Tese de doutorado em Musicologia e Etnomusicologia europeia. EHESS/Universidade Humboldt, 2013.

CALADO, Carlos. Tropicália: a história de uma revolução musical. São Paulo: Ed. 34, 1997.

COHN, Sérgio (org.). Encontros: Gilberto Gil. Rio de Janeiro, Azougue, 2008.

COHN, Sergio; COELHO, Frederico (orgs.). Encontros: Tropicália. Rio de Janeiro: Azougue, 2007, p. 233.

CONTIER, Arnaldo. Edu Lobo e Carlos Lyra: o nacional e o popular na canção de protesto (os anos 1960). Revista Brasileira de História, v. 18, n. 35, São Paulo, 1998, p. 13-52.

CONVERSA com Gilberto Gil. In: CAMPOS, Augusto de (org.). Balanço da bossa e outras bossas. São Paulo: Perspectiva, [1968] 2008.

COQUERY-VIDROVITCH, Catherine. Festan, Festac, Panaf. In: FLÉCHET, Anaïs; GOETSCHEL, Pascale; et al. (orgs.). Une histoire des festivals: XXe-XXIe siècles. Paris: Publications de la Sorbonne, 2013, p. 317-330.

COSTA, Eliana. Jangada digital: Gilberto Gil e as políticas públicas para a cultura das redes. Rio de Janeiro: Azougue, 2011.

COUTINHO, Marcelo. Ministério da Cultura cresce no cenário cultural internacional. Portal da Cultura, 24 jan. 2008. Entrevista de Marcelo Coutinho, diretor do Comissariado da Cultura Brasileira no Mundo. Disponível em: <http:/ / thacker.diraol.eng.br/mirrors/www.cultura.gov.br/site/2008/01/24/entrevista/index.html>

DUNN, Christopher. Brutality garden: Tropicália and the emergence of a brazilian counterculture. Chapel Hill/Londres: University of North Carolina Press, 2001. 
EU QUERO é mel. Veja, 10 jan. 1979. Entrevista de Gil a Décio Bar e Regina Echeverria.

FAVARETTO, Celso. Tropicália, alegoria, alegria. São Paulo: Ateliê, [1979] 2000.

FELD, Steven. Une si douce berceuse pour la world music. L'Homme, 171-172, 2004, p. 389-408.

FICO, Carlos. Como eles agiam: os subterrâneos da ditadura militar. Rio de Janeiro: Record, 2001.

FIQUET, Eloi; GALLIMARDET, Loraine. On ne peut nier longtemps l'art nègre: enjeux du colloque et de l'exposition du premier festival mondial des Arts nègres de Dakar en 1966. Gradhiva, 10, 2009, p. 134-154.

FLÉCHET, Anaïs. "Si tu vas à Rio..." : la musique populaire brésilienne en France au XXe siècle. Paris, Armand Colin, 2013.

As partituras da identidade: o Itamaraty e a música brasileira no século XX. In: SUPPO, Hugo Rogélio; LESSA, Mônica Leite (orgs.). A quarta dimensão das relações internacionais: as relações culturais. Rio de Janeiro: Contra Capa/Faperj, 2012, p. 139167.

GIL FALA a Odete Lara. O Pasquim, 15 out. 1969. Entrevista de Gil a Odete Lara.

GILBERTO GIL. Entrevista para à Playboy. Playboy, jun. 2007. . Recuso + aceito = receito. O Pasquim, 25 ago. 1970.

GILBERTO Gil espera tranquilo outra vaia. Jornal da Tarde, 04 out. 1967.

GILROY, Paul. L'Atlantique noir: modernité et double conscience. Paris: Kargo, [1993] 2003.

LAFARGUE, François. Le Brésil, une puissance africaine?. Afrique contemporaine, 2008/4, 228, p. 137-150.

LESPRIT, Bruno. À la Bastille, un concert pour célébrer l'amitié franco-brésilienne. Le Monde, 14 jul. 2005. 
MALLET, Julien. Ethnomusicologie des 'jeunes musiques'. L'Homme, 171-172, 2004, p. 477-488.

MARQUES, Joseph C. International relations in portuguese: Brazil and the CPLP. Anais do XI Congresso da Brazilian Studies Association, Universidade de Illinois, EUA, 6 a 9 set. 2012. Disponível em: <http://www.brasa.org/ wordpress/Documents/BRASA_XI/Joseph-Marques.pdf>.

MARTIN, Denis-Constant. Who's afraid of the bad world music?: désir de l'autre, processus hégémoniques et flux transnationaux mis en musique dans le monde contemporain. Cahiers de musiques traditionnelles, 9, 1996, p. 3-21.

NAPOLITANO, Marcos. The era of song festivals: a fundamental moment in Música Popular Brasileira (MPB). In: FLÉCHET, Anaïs; GOETSCHEL, Pascale; et al. (orgs.). Une histoire des festivals: XXe-XXIe siècles. Paris: Publications de la Sorbonne, 2013, p. 79-88.

- A síncope das ideias: a questão da tradição na música popular brasileira. São Paulo: Fundação Perseu Abramo, 2007.

A MPB sob suspeita: a cena musical vista pela ótica dos serviços de vigilância política (1968-1981). Revista Brasileira de História, v. 24, n. ํ 47, São Paulo, 2004.

. "Seguindo a canção": engajamento político e indústria cultural na MPB (19591969). São Paulo: Annablume, 2001.

NASCIMENTO, Abdias do. O genocídio do negro brasileiro: processo de um racismo mascarado. Rio de Janeiro: Paz e Terra, 1978.

NYE, Joseph. Soft power: the means to success in the world politics. Nova York: PublicAffairs, 2004.

O FUMO não é Deus nem é o diabo. Boca do inferno, Salvador, 1976. Entrevista de Gil a João Santana Filho.

O SOM universal (de Caetano e Gil). Folha de S. Paulo, 12 out. 1967.

O SONHO acabou. Gil está sabendo de tudo. O Bondinho, 16 fev. 1972. Entrevista de Gilberto Gil a Hamilton Almeida. 
QUE CAMINHO seguir na música brasileira? Civilização Brasileira, n. 7, mai. 1966, p. 375-385.

RIDENTI, Marcelo. Em busca do povo brasileiro: artistas da revolução, do CPC à era da TV. São Paulo: Record, 2000.

SARAIVA, José Flávio Sombra. África parceira do Brasil atlântico: relações internacionais do Brasil e da África no início do século XXI. Belo Horizonte, Fino Traço, 2012.

. O lugar da África: a dimensão atlântica da política externa brasileira (de 1946 a nossos dias). Brasília: Ed. UnB, 1996.

SOARES, Maria Susana Arrosa. A diplomacia cultural no Mercosul. Revista Brasileira de Política Internacional, 51/1, 2008, p. 53-69.

TAYLOR, Tim. Global pop: world music, world markets. New York: Routledge, 1997.

TERRA, Renato; CALIL, Ricardo. Uma noite em 67. Videofilmes Produções Artísticas, 2010.

TURINO, Célio. Ponto de Cultura: o Brasil de baixo para cima. 2. ed. São Paulo: Anita Garibaldi, 2010.

VELOSO, Caetano. Verdade tropical. São Paulo: Companhia das Letras, 1997.

WHITE, Bob W. Rethinking globalization through music. In: WHITE, Bob W. (org.). Music and globalization: critical encounters. Bloomington: Indiana University Press, 2011, p. 1-14.

ZAN, José Roberto. Funk, soul e jazz na terra do samba: a sonoridade da Banda Black Rio. ArtCultura, Uberlândia, v. 7, n. 11, jul./dez., 2005, p. 183-196. 